\title{
Mycoplasma iguanae sp. nov., from a green iguana (Iguana iguana) with vertebral disease
}

Correspondence

D. R. Brown

brownd@mail.vetmed.ufl.edu

\author{
D. R. Brown, ${ }^{1}$ D. L. Demcovitz, ${ }^{1}$ D. R. Plourdé, ${ }^{1}$ S. M. Potter, ${ }^{1}$ M. E. Hunt, ${ }^{1}$ \\ R. D. Jones ${ }^{2}$ and D. S. Rotstein ${ }^{2}$
}

\author{
${ }^{1}$ Department of Pathobiology, College of Veterinary Medicine, University of Florida, Gainesville, \\ FL 32611-0880, USA \\ ${ }^{2}$ Department of Pathobiology, University of Tennessee, Knoxville, TN 37996-4542, USA
}

\begin{abstract}
Strain $2327^{\top}$, first cultured from vertebral abscesses of green iguanas (Iguana iguana) collected in Florida, USA, was readily distinguished from all previously described mollicutes by $16 \mathrm{~S}$ rRNA gene sequence comparisons. Strain $2327^{\top}$ lacks a cell wall, ferments glucose, does not hydrolyse arginine, aesculin or urea and is sensitive to digitonin. Western blots distinguished the novel isolate serologically from the most closely related members of the Mycoplasma neurolyticum cluster. On the basis of these data, the isolate represents a novel species for which the name Mycoplasma

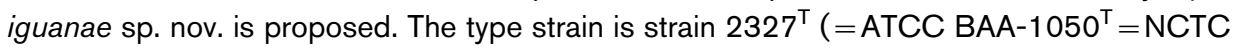
$\left.11745^{\top}\right)$.
\end{abstract}

Reptiles are susceptible to infection with diverse mycoplasmas and experience the same range of effects of mycoplasmosis as other vertebrates (Brown, 2002). Two feral subadult female green iguanas (Iguana iguana) collected in Florida, USA, were examined by necropsy. Mycoplasmas were cultured from vertebral abscesses present in each iguana. Isolates cloned from colonies obtained from each of the iguanas had identical 16S rRNA gene sequences and phenotypic characteristics. In this paper, one of the strains, strain $2327^{\mathrm{T}}$, is characterized and compared with previously described mollicutes.

Primary isolation from abscess material was on blood agar incubated at $35{ }^{\circ} \mathrm{C}$ in $5 \% \mathrm{CO}_{2}$. Alpha-haemolytic colonies were observed after 4 days, but Gram-stained cells were not visible by bright-field microscopy at $\times 1000$ magnification. Colonies were passaged to American Type Culture Collection (ATCC) medium 988 (SP-4) agar, $\mathrm{pH} 7 \cdot 6-7 \cdot 8$. Two triply-filter-cloned isolates (Tully, 1983), one from each iguana and designated as strains 2130 and $2327^{\mathrm{T}}$, were characterized. Colonies of the organism were approximately $175 \mu \mathrm{m}$ in diameter and variable in appearance (convex to umbonate, with entire, or occasionally curled, margins) when examined at $\times 20$ magnification after 3-4 days growth on SP-4 agar at 30 or $37^{\circ} \mathrm{C}$ (Fig. 1). Mature colonies

Published online ahead of print on 25 November 2005 as DOI 10.1099/ijs.0.63852-0.

The GenBank/EMBL/DDBJ accession number for the 16S rRNA gene sequence of strain $2327^{\top}$ is $A Y 714305$.

A transmission electron micrograph of cells of $M$. iguanae sp. nov. and figures demonstrating total protein patterns of the novel strains after SDS-PAGE and immunogen patterns of the strains on a Western blot are available as supplementary material in IJSEM Online. had sectored centres remarkably similar to those typical of Mycoplasma molare. Their sharp margins, without a tendency to generate satellite colonies on SP-4 agar, indicated that the isolates were non-motile (International Committee on Systematic Bacteriology Subcommittee on the Taxonomy of Mollicutes, 1995). The maximal growth rate occurred at $37^{\circ} \mathrm{C}$, as indicated by acidification of SP-4 broth supplemented with glucose and incubated in ambient air without agitation. The organisms grew more slowly in broth at 25,30 and $42^{\circ} \mathrm{C}$, but did not grow at 4 or $45^{\circ} \mathrm{C}$. The organisms grew on agar anaerobically at 25 and $30^{\circ} \mathrm{C}$. Cells of strain $2327^{\mathrm{T}}$ in the exponential phase of growth appeared as pleomorphic forms, between 200 and $800 \mathrm{~nm}$ in size and

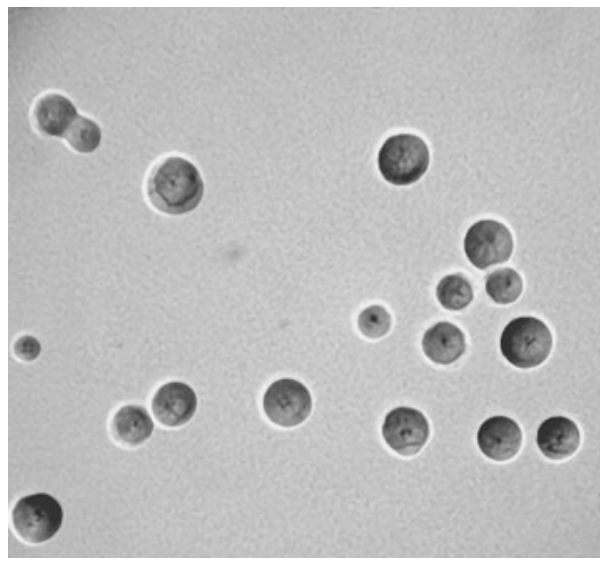

Fig. 1. Typical colony morphology of $M$. iguanae $2327^{\top}$ after $96 \mathrm{~h}$ growth on SP-4 agar at $37^{\circ} \mathrm{C}$ in an atmosphere containing $5 \% \mathrm{CO}_{2}$. A typical colony has a diameter of $175 \mu \mathrm{m}$. 
surrounded by a trilaminar unit membrane. A transmission electron micrograph of a thin section of cells of strain $2327^{\mathrm{T}}$ is available as Supplementary Fig. S1 in IJSEM Online.

The following analytical procedures were performed: fermentation tests (Razin \& Cirillo, 1983), hydrolysis of arginine, aesculin and urea (Aluotto et al., 1970) and requirement for sterol (Rose et al., 1993; Tully, 1995). Appropriate control cultures of Acholeplasma laidlawii, Mycoplasma alligatoris, Mycoplasma bovis, Mycoplasma hominis and Ureaplasma urealyticum were obtained from the ATCC. Both novel isolates produced acid from arabinose, galactose, glucose, lactose, mannose, melibiose, rhamnose, sucrose and trehalose and also from adonitol, inositol, mannitol and sorbitol. Strains 2130 and $2327^{\mathrm{T}}$ did not hydrolyse arginine, aesculin or urea. Both novel isolates grew in SP-4 broth containing 20, 2 or $0 \cdot 2 \% \mathrm{v} / \mathrm{v}$ fetal bovine serum, but neither strain could be passaged in serum-free medium. Both novel strains were sensitive to digitonin, with 22-26 $\mathrm{mm}$ diameter zones of inhibition.

The partial 16S rRNA gene sequence of strain $2327^{\mathrm{T}}$ was determined as previously described (Brown et al., 2001) and matched to the small-subunit rRNA gene sequences in the Ribosomal Database Project release 8.1 by using SEQUENCE_ MATCH version 2.7 (Cole et al., 2003). The best match (score $=0.661$ ) was to Mycoplasma neurolyticum Sabin $\mathrm{A}^{\mathrm{T}}$, positioning strain $2327^{\mathrm{T}}$ in the M. neurolyticum phylogenetic cluster (Johansson \& Pettersson, 2002). A Kimura twoparameter distance matrix (Felsenstein, 1989) was then calculated to identify closely related type species within that cluster (Mycoplasma lagogenitalium, M. molare, M. neurolyticum, Mycoplasma conjunctivae, Mycoplasma bovoculi, Mycoplasma flocculare, Mycoplasma hyopneumoniae and Mycoplasma ovipneumoniae; matrix similarity scores of $0 \cdot 954,0 \cdot 950,0 \cdot 930,0 \cdot 904,0 \cdot 897,0 \cdot 897,0.889$ and 0.888 , respectively; Fig. 2). Similarity scores of this magnitude have been considered to provide substantial evidence that the isolate being compared represents a distinct species (Stackebrandt et al., 2002; Stackebrandt \& Goebel, 1994). The similarity scores were used as the basis for selecting antisera available from the Mollicutes Reference Collection to use for serological comparisons.

Serological tests were performed by using rabbit polyclonal antiserum against strain $2327^{\mathrm{T}}$ and the Mycoplasma species listed above. To prepare strain $2327^{\mathrm{T}}$ antiserum, two rabbits were immunized with $200 \mu \mathrm{g}$ strain $2327^{\mathrm{T}}$ whole-cell lysate plus RIBI adjuvant on days 1, 21, 35 and 49 of a 70-day protocol. Both rabbits had strongly seroconverted by the end of the protocol, as assessed by Western blots of homologous antigen (Brown et al., 2001) and the terminal sera were pooled for growth and metabolism inhibition tests (Clyde, 1983; Taylor-Robinson, 1983) and epi-immunofluorescence tests (Gardella et al., 1983). The results of those tests were surprisingly equivocal, but a Western blot of strain $2327^{\mathrm{T}}$ whole-cell lysate was a discriminating serological test in support of the $16 \mathrm{~S}$ rRNA gene sequence comparisons to demonstrate the status of strain $2327^{\mathrm{T}}$ as a representative of a unique species (Rosselló-Mora \& Amann, 2001). Blots revealed immunogenic similarities only to $M$. neurolyticum Sabin $\mathrm{A}^{\mathrm{T}}$ (Fig. 3), giving further support for the assignment of strain $2327^{\mathrm{T}}$ to the M. neurolyticum clade, although the banding pattern of strain $2327^{\mathrm{T}}$ was clearly different from that of $M$. neurolyticum.

The two isolates described were obtained from green iguanas with multifocal abscesses of the coccygeal and thoracic vertebrae, characterized histopathologically by marked Wallerian degeneration of the spinal cord white matter, fibrosis, vertebral osteomalacia and epaxial myofibre degeneration. Other clinical findings included lymphoplasmacytic enteritis and megacolon and systemic effects reflecting mixed bacterial septicaemia, possibly secondary to mycoplasma-induced spinal cord damage, and neuronal deficits affecting the colon that set the stage for invasion by enteric bacteria, although a causal association with disease has not yet been established. Lung, spleen and liver samples and swabs of the coelomic cavity of the necropsied iguanas were also cultured, but mycoplasmas were not isolated from any sites other than the vertebrae.

The properties of strain $2327^{\mathrm{T}}$ described herein fulfil the criteria for assignment to the class Mollicutes (International Subcommittee on the Taxonomy of the Mollicutes, 1995), including absence of a cell wall, filterability and penicillin resistance. The non-helical morphology of strain $2327^{\mathrm{T}}$, optimum growth temperature of $37^{\circ} \mathrm{C}$ and its inability to hydrolyse urea place the novel strain within the order Mycoplasmatales, family Mycoplasmataceae. A requirement for sterol, inability to hydrolyse aesculin and the presence of

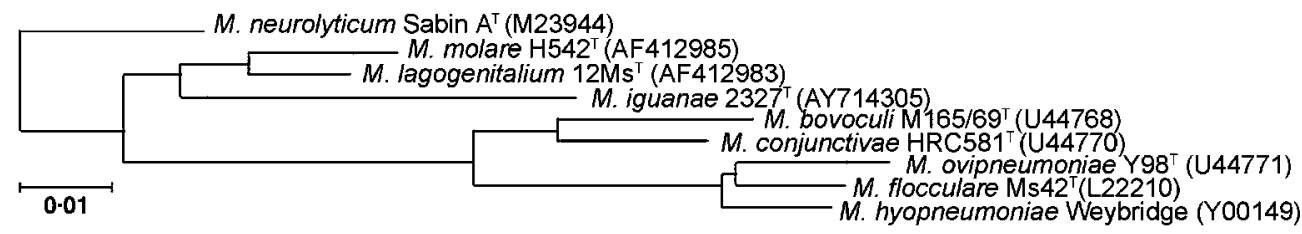

Fig. 2. Unrooted neighbour-joining phylogram of $16 \mathrm{~S}$ rRNA gene sequences of type strains of species within the Mycoplasma neurolyticum clade most similar to the $16 \mathrm{~S}$ rRNA gene sequence of $M$. iguanae $2327^{\top}$. The phylogram was generated by using the PHYLIP program NEIGHBOR with default parameters (Felsenstein, 1989). Bar, 0.01 substitutions per site. 


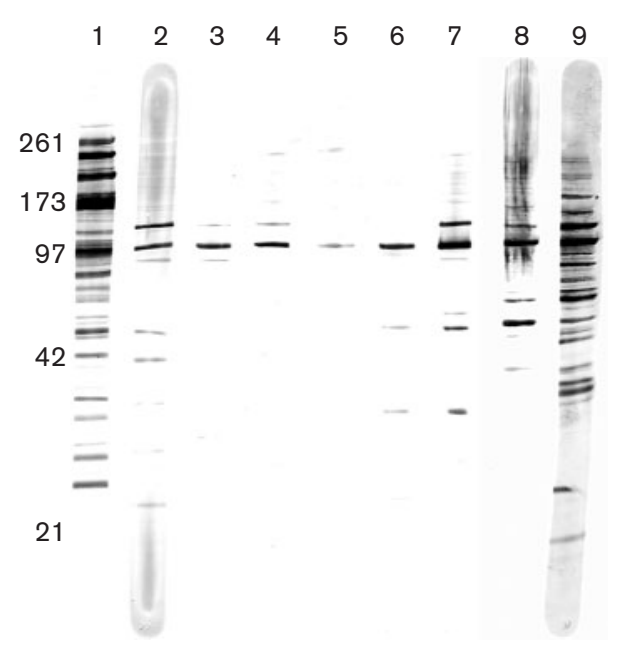

Fig. 3. Western blot of $M$. iguanae $2327^{\top}$ whole-cell lysate probed with polyclonal antisera against: $1, M$. iguanae $2327^{\top}$; 2, Mycoplasma bovoculi M165/69'; 3, Mycoplasma conjunctivae HRC581 ${ }^{\top} ; 4$, Mycoplasma flocculare Ms42 ${ }^{\top} ; 5$, Mycoplasma hyopneumoniae $\mathrm{J}^{\mathrm{T}}$; 6 , Mycoplasma lagogenitalium $12 \mathrm{Ms}^{\top}$;

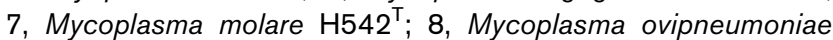
931; 9, Mycoplasma neurolyticum Sabin $A^{\top}$. The image was digitized by using an Alphalmager (Alpha Innotech). Contrast was normalized for better clarity by using the auto contrast feature after cropping and alignment with Adobe Photoshop CS 8.0 (Adobe Systems). The apparent molecular mass is indicated $(\mathrm{kDa})$.

conserved 16S rRNA gene sequences indicate that the organism belongs in the genus Mycoplasma. Finally, the unique $16 \mathrm{~S}$ rRNA gene sequence of strain $2327^{\mathrm{T}}$, which has less than $97 \%$ similarity to that of any previously recognized species (Stackebrandt \& Goebel, 1994), demonstrates its association with the M. neurolyticum phylogenetic cluster. Accordingly, strain $2327^{\mathrm{T}}$ represents a novel species, for which the name Mycoplasma iguanae is proposed.

Supplementary figures that demonstrate the uniformity of total protein patterns of M. iguanae strains 2130 and $2327^{\mathrm{T}}$ by Coomassie staining after SDS-PAGE (Supplementary Fig. S2, available in IJSEM Online) and the uniformity of their immunogen patterns on a Western blot probed with strain $2327^{\mathrm{T}}$ antiserum (Supplementary Fig. S3) support the genetic, phenotypic and ecological evidence that the two novel strains represent the same species (Stackebrandt et al., 2002).

\section{Description of Mycoplasma iguanae sp. nov.}

Mycoplasma iguanae (ig.ua'nae. N.L. fem. gen. sing. n. iguanae of the iguana lizard).

Cells are pleomorphic in shape, varying from 200 to $800 \mathrm{~nm}$ in diameter. Cells are devoid of cell wall and surrounded only by a cytoplasmic membrane. Non-helical and nonmotile. Cells are filterable through $220 \mathrm{~nm}$ membranes.
Colonies on solid medium with $0 \cdot 8 \%$ agar exhibit variable forms. Chemo-organotrophic. Acid produced from glucose. Does not hydrolyse arginine, aesculin or urea. Serum or sterol required for sustained growth. Temperature range $25-42^{\circ} \mathrm{C}$, with maximum growth rate at $37^{\circ} \mathrm{C}$. Unique $16 \mathrm{~S}$ rRNA gene sequence unequivocally distinct from the most closely related recognized species in the Mycoplasma neurolyticum phylogenetic cluster.

The type strain, strain $2327^{\mathrm{T}}\left(=\right.$ ATCC BAA $-1050^{\mathrm{T}}=$ NCTC $11745^{\mathrm{T}}$ ), was isolated from a vertebral abscess of a feral green iguana (Iguana iguana) from southern Florida, USA.

\section{Acknowledgements}

Electron microscopy, nucleotide sequencing and M. iguanae strain $2327^{\mathrm{T}}$ antiserum purification were performed by the Interdisciplinary Center for Biotechnology Research at the University of Florida. David Windsor of Mycoplasma Experience Ltd (Surrey, UK) facilitated deposition of NCTC 11745. We thank Robert Whitcomb for advice on minimum standards for the description of novel species of mycoplasmas. Researchers interested in access to the reference collection of antisera which originated at the US National Institute of Allergy and Infectious Diseases Laboratory should contact the Mollicutes Culture Collection at Purdue University. M. iguanae strain $2327^{\mathrm{T}}$ and homologous antiserum have been deposited into that collection.

\section{References}

Aluotto, B. B., Wittler, R. G., Williams, C. O. \& Faber, J. E. (1970). Standardized bacteriologic techniques for the characterization of Mycoplasma species. Int J Syst Bacteriol 20, 35-58.

Brown, D. R. (2002). Mycoplasmosis and immunity of fish and reptiles. Front Biosci 7, 1338-1346.

Brown, D. R., Farley, J. M., Zacher, L. A., Carlton, J. M.-R., Clippinger, T. L., Tully, J. G. \& Brown, M. B. (2001). Mycoplasma alligatoris sp. nov., from American alligators. Int J Syst Evol Microbiol 51, 419-424.

Clyde, W. A. (1983). Growth inhibition tests. Methods in Mycoplasmology 1, 405-410.

Cole, J. R., Chai, B., Marsh, T. L. \& 8 other authors (2003). The Ribosomal Database Project (RDP-II): previewing a new autoaligner that allows regular updates and the new prokaryotic taxonomy. Nucleic Acids Res 31, 442-443.

Felsenstein, J. (1989). PHYLIP-Phylogeny Inference Package (version 3.2). Cladistics 5, 164-166.

Gardella, R. S., Del Giudice, R. A. \& Tully, J. G. (1983). Immunofluoresence. Methods in Mycoplasmology 1, 411-439.

International Committee on Systematic Bacteriology Subcommittee on the Taxonomy of Mollicutes (1995). Revised minimum standards for the description of new species of the class Mollicutes (Division Tenericutes). Int J Syst Bacteriol 45, 605-612.

Johansson, K.-E. \& Pettersson, B. (2002). Taxonomy of Mollicutes. In Molecular Biology and Pathogenicity of Mycoplasmas, pp. 1-30. Edited by S. Razin \& R. Herrmann. New York: Kluwer Academic/ Plenum.

Razin, S. \& Cirillo, V. P. (1983). Sugar fermentation. Methods in Mycoplasmology 1, 337-344. 
Rose, D. L., Tully, J. G., Bove, J. M. \& Whitcomb, R. F. (1993). A test for measuring growth responses of mollicutes to serum and polyoxyethylene sorbitan. Int J Syst Bacteriol 43, 527-532.

Rosselló-Mora, R. \& Amann, R. (2001). The species concept for prokaryotes. FEMS Microbiol Rev 25, 39-67.

Stackebrandt, E. \& Goebel, B. M. (1994). Taxonomic note: a place for DNA-DNA reassociation and 16S rRNA sequence analysis in the present species definition in Bacteriology. Int J Syst Bacteriol 44, 846-849.

Stackebrandt, E., Frederiksen, W., Garrity, G. M. \& 10 other authors (2002). Report of the ad hoc committee for the re-evaluation of the species definition in bacteriology. Int J Syst Evol Microbiol 52, 1043-1047.

Taylor-Robinson, D. (1983). Metabolism inhibition tests. Methods in Mycoplasmology 1, 411-417.

Tully, J. G. (1983). Cloning and filtration techniques for mycoplasmas. Methods in Mycoplasmology 1, 173-177.

Tully, J. G. (1995). Determination of cholesterol and polyoxyethylene sorbitan growth requirements of mollicutes. In Molecular and Diagnostic Procedures in Mycoplasmology, vol. 1, pp. 381-389. Edited by S. Razin \& J. G. Tully. San Diego, CA: Academic Press. 